\title{
Novel retail technologies and marketing analytics
}

\author{
Maria Petrescu $^{1}$ Anjala S. Krishen ${ }^{2}$
}

Published online: 14 August 2018

(c) Springer Nature Limited 2018

Retailers utilize the latest technology for obtaining consumer data and marketing analytics including IP addresses, geo-fencing data, beacons, behavioral data from the Internet of Things, automated facial recognition data, and radio frequency identification (RFID) tags (Andrews et al. 2016; Blázquez 2014; Lewinski et al. 2016; Luo et al. 2014; Roh et al. 2009). Studies show the value of geo-conquesting, a method of competitive locational targeting enacted by sending mobile promotions to consumers near a competitor's location (Fong et al. 2015). It is essential to understand how these new technologies can collect marketing information and analytics in a retail environment, and the obstacles they present, especially in terms of data privacy and security. Considering the development of new regulations, such as the European GDPR, more studies are needed on these topics, to assess novel retail technologies for obtaining high-quality marketing analytics. In the following, we present some examples of technologies and potential future research that could contribute to improving the use of marketing analytics in retailing.

\section{RFID}

RFID tags are tiny chip sets that can identity products; they constitute one of the main components of the Internet of Things. The technology includes four parts: RFID tags,

Maria Petrescu

mpetresc@nova.edu

Anjala S. Krishen

anjala.krishen@unlv.edu

1 Nova Southeastern University, Fort Lauderdale, FL, USA

2 University of Nevada, Las Vegas, USA readers and antennas, RFID middleware, and back-end RFID enterprise service (Fiorito et al. 2010; Roh et al. 2009). Open-loop RFID applications track items from a starting point to a terminal destination, as in from a manufacturer to a store, with passive, low-cost RFID tags or with battery-powered active RFID tags, like tracking shopping carts or visitor ID's through a store (Heim et al. 2009; Kumar et al. 2009).

The benefits of RFID include improved accuracy in managing inventory, reduced logistical costs, improved customer service, communication, and capacity to hold more information (Park et al. 2010; Reyes et al. 2016; Slettemeås 2009). However, there are also many issues that impede the use of RFID technologies. For example, when considering the new GDPR, retailers should consider issues surrounding consent and transparency. For example, an RFID privacy impact assessment process could be enacted so that such information would be required by operators of RFID application systems. The new EU regulations refer to RFID chips as an example of identification technology that is especially relevant in the context of wearable technology. According to GDPR, any personal information captured through RFID should be completed through a process that is both lawful and ensures appropriate security and confidentiality.

Research shows that the main issues related to the use of RFID in retailing are privacy and security, difficulty with standardization, technical bugs, and high costs (Leung et al. 2014; Roh et al. 2009; Slettemeås 2009; Wu et al. 2012; Zhu et al. 2012). Regarding privacy, research notes that RFID tags can be scanned by anyone with an RFID scanner, providing potential leeway for external entities to access data encoded on RFID tags (Park et al. 2010; Wu et al. 2012; Zhu et al. 2012). Studies emphasize that when an RFID system is installed, the integrity of the tags is 
paramount to preventing unauthorized tracking and data interception (Reyes et al. 2016). Under these circumstances, data privacy and security in RFID use, in addition to consumer attitudes and perceptions towards this technology, influences marketing analytics outcomes and warrants further research.

\section{Geo-fencing and geo-conquesting}

Geo-fencing includes the ability to separate workloads within a trusted compute pool on known hosts in authorized geographies and servers. IBM, Intel, VMware, and HyTrust provide varying solutions that ensure the decryption and processing of data from specified locations. Solutions such as HyTrust offer the ability to log administrator actions by individual, so evidence-based audits and reports can be generated and utilized as an effective marketing analytics source. As illustrated by research, approximately 3 billion consumers own smartphones globally. Geo-fenced mobile ads, sent to consumers in the virtual perimeter of a store, are considered an optimal mechanism to convince customers to try a store and shop inside. Moreover, geo-conquest ads target consumers near competitors' stores (Andrews 2017; Andrews et al. 2016).

Considering the need for organizations to meet GDPR requirements, as well as HIPAA, PCI, and more, data security is a significant concern with geo-fencing, especially in the context of cloud adoption. As such, research studies could focus on not only how geo-fencing and geoconquesting can help marketing analytics in the retailing sector, but also on how the use of these location-based technologies influence consumers' perceptions of privacy (Krishen et al. 2017; Raschke et al. 2014).

\section{Facial recognition systems}

Research shows the benefits of measuring consumer emotions and attention during visits to retail locations and its potential to provide helpful insight to marketers (Lewinski et al. 2014, 2016). Studies also note that automated facial recognition systems can assess objective emotion responses with near-human accuracy rates (Lewinski et al. 2014, 2016). This technology can also be used to help with counting people, monitoring visitor movement and attraction patterns, and tracking and profiling (Lewinski et al. 2016; Liu et al. 2017). However, these practices may infringe on an individual's right to their own image, which is protected as part of the right to privacy. Consumer reaction to the use of facial recognition systems is a major topic of research, especially with an emphasis on the limits and conditions of usage for this type of technology.
Additionally, complications related to the collection of information through this technology and data processing should be analyzed in the context of individual rights to privacy and data management.

In general, future research should focus on how retailers handle consumer privacy concerns while simultaneously using new technologies to collect marketing analytics about their customers and customer behavior.

\section{References}

Andrews, M. 2017. Increasing the effectiveness of mobile advertising by using contextual information. Mobile Advertising 9 (2): $37-42$.

Andrews, M., et al. 2016. Mobile ad effectiveness: Hyper-contextual targeting with crowdedness. Marketing Science 35 (2): 218-233. https://doi.org/10.1287/mksc.2015.0905.

Blázquez, M. 2014. Fashion shopping in multichannel retail: The role of technology in enhancing the customer experience. International Journal of Electronic Commerce 18 (4): 97-116. https:// doi.org/10.2753/jec1086-4415180404.

Fiorito, S.S., M. Gable, and A. Conseur. 2010. Technology: Advancing retail buyer performance in the twenty-first century. International Journal of Retail and Distribution Management 38 (11): 879-893. https://doi.org/10.1108/09590551011085966.

Fong, N.M., Z. Fang, and X. Luo. 2015. Geo-conquesting: Competitive locational targeting of mobile promotions. Journal of Marketing Research 52 (5): 726-735. https://doi.org/10.1509/ jmr.14.0229.

Heim, G.R., W.R. Wentworth, and X. Peng. 2009. The value to the customer of RFID in service applications. Decision Sciences 40 (3): 477-512. https://doi.org/10.1111/j.1540-5915.2009.00237.x.

Krishen, A.S., R.L. Raschke, A.G. Close, and P. Kachroo. 2017. A power-responsibility equilibrium framework for fairness: Understanding consumers' implicit privacy concerns for locationbased services. Journal of Business Research 73 (4): 20-29. https://doi.org/10.1016/j.jbusres.2016.12.002.

Kumar, S., M.J. Anselmo, and K.J. Berndt. 2009. Transforming the retail industry: Potential and challenges with RFID technology. Transportation Journal 48(4): 61-71. http://search.proquest. com/docview/204599600?accountid=15533.

Leung, J., W. Cheung, and S.C. Chu. 2014. Aligning RFID applications with supply chain strategies. Information and Management 51 (2): 260-269. https://doi.org/10.1016/j.im. 2013.11.010.

Lewinski, P., J. Trzaskowski, and J. Luzak. 2016. Face and Emotion Recognition on Commercial Property under EU Data Protection Law. Psychology \& Marketing 33 (9): 729-746. https://doi.org/ 10.1002/mar.20913.

Lewinski, P., T. M. den Uyl, and C. Butler. 2014. Automated facial coding: Validation of basic emotions and FACS AUs recognition in FaceReader. Journal of Neuroscience, Psychology, and Economics 7 (4): 227-236. https://doi.org/10.1037/npe0000028.

Liu, J., Y. Gu, and S. Kamijo. 2017. Customer behavior classification using surveillance camera for marketing. Multimedia Tools and Applications 76 (5): 6595-6622. https://doi.org/10.1007/s11042016-3342-1.

Luo, X., et al. 2014. Mobile targeting. Marketing Science 60 (7): 1738-1756. https://doi.org/10.1287/mnsc.2013.1836.

Park, K.S., C.E. Koh, and K. Nam. 2010. Perceptions of RFID technology: A cross-national study. Industrial Management and 
Data Systems 110 (5): 682-700. https://doi.org/10.1108/ 02635571011044722.

Raschke, R., A.S. Krishen, and P. Kachroo. 2014. Understanding the components of information privacy threats for location-based services. Journal of Information Systems 28 (1): 227-242.

Reyes, P.M., S. Li, and J.K. Visich. 2016. Determinants of RFID adoption stage and perceived benefits. European Journal of Operational Research 254 (3): 801-812. https://doi.org/10.1016/ j.ejor.2016.03.051.

Roh, J.J., A. Kunnathur, and M. Tarafdar. 2009. Classification of RFID adoption: An expected benefits approach. Information and Management 46 (6): 357-363. https://doi.org/10.1016/j.im.2009. 07.001 .
Slettemeås, D. 2009. RFID—The "next step" in consumer-product relations or Orwellian nightmare? Challenges for research and policy. Journal of Consumer Policy 32 (3): 219-244. https://doi. org/10.1007/s10603-009-9103-z.

Wu, Y.A., et al. 2012. A nomological model of RFID privacy concern. Business Process Management Journal 18 (3): 420-444. https://doi.org/10.1108/14637151211232623.

Zhu, X., S.K. Mukhopadhyay, and H. Kurata. 2012. A review of RFID technology and its managerial applications in different industries. Journal of Engineering and Technology Management 29 (1): 152-167. https://doi.org/10.1016/j.jengtecman.2011.09. 011. 